\title{
Run of River Bulk Hydroelectric Generation from the Congo River without a Conventional Dam
}

\author{
${ }^{1}$ Thomas J. Hammons, ${ }^{2}$ Pathmanathan Naidoo, ${ }^{3}$ Lawrence Musaba \\ ${ }^{1}$ International Practices for Energy Development and Power Generation, University of Glasgow, Glasgow, UK; ${ }^{2}$ Eskom, South Af- \\ rica; ${ }^{3}$ Coordination Center Manager, Southern African Power Pool, Harare, Zimbabwe. \\ E-mail: T.Hammons@btinternet.com
}

Received November $17^{\text {th }}, 2010$; revised January $19^{\text {th }}, 2011$; accepted January $28^{\text {th }}, 2011$.

\begin{abstract}
The paper discusses harvesting the Congo River for bulk hydroelectric generation based on run of river, low head generation technology, as employed at the existing Inga 2 power station in the Democratic Republic of Congo. The evolutionary approach builds on existing infrastructure. The results show that the footprint is much smaller than that which employs a conventional dam. The environmental impact is minimized. These collectively will contribute to lower capital costs. In summary, $10000 \mathrm{~cm}^{3} / \mathrm{sec}$ of constant river flow will produce $5000 \mathrm{MW}$ of base power. On average, the constant recorded flow of the river is $30000 \mathrm{~cm}^{3} / \mathrm{sec}$ and a total of $15000 \mathrm{MW}$ of base power generation is possible.
\end{abstract}

Keywords: Hydroelectric Power Generation, River Engineering, Environmental Impact, Hydropower Development in $D R C$

\section{Introduction}

The proposed Western Power Corridor Project is designed to tap the naturally renewable hydroelectric energy from the river networks located on the west coast of Southern Africa. The project was unanimously supported by the joint sitting of the Executive Committee of the Southern African Power Pool as a SADC/NEPAD priority project that will contribute to the economic renaissance of the African Continent [1]. Under the auspices of the Southern African Power Pool, five national state enterprises were tasked to lead and develop the project, namely, SNEL (DRC), ENE (Angola), Nampower (Namibia), BPC (Botswana), and Eskom (South Africa). All the five national state enterprises have equal contributions to the project and own $20 \%$ of the share capital of the joint venture company, WESTCOR.

The naturally renewable hydroelectric sources are located on the Congo River in the Democratic Republic of Congo, on the Medico Quanza River in Angola and on the lower Kunene River in Northern Namibia.

To commence the project, SNEL have submitted specifically for the INGA 3 Power Station site for the proposed WESTCOR development. SNEL owns and operates the two existing power stations, Inga 1 and 2, with a combined output of $1770 \mathrm{MW}$. Inga 3 is the next phase of the development of the Inga site, with a rated output of $3500 \mathrm{MW}$. Here water is extracted from the common
Inga 1 and 2 pool and produce the $3500 \mathrm{MW}$ at a head of $60 \mathrm{~m}$.

Further work by SNC Lavalin of Canada who have conducted the feasibility study under a CIDA grant have advised that on repositioning the underground tunnels further into the river bed, then a head of $100 \mathrm{~m}$ is achieved with a pipeline length of $9 \mathrm{~km}$ and a further 4 $320 \mathrm{MW}$ could be generated. Additional studies are in progress and an aspiration is a power station of 10000 MW at Inga 3; either one station at $10000 \mathrm{MW}$ or an Inga 3 and an Inga 4 at $5000 \mathrm{MW}$ each. The final phase of the Inga site development is Grand Inga, with a potential rated output of some $40000 \mathrm{MW}$. In total, the Congo River has a full 100000 MW capability and all potential sites need to be investigated and loaded into forward generation plans.

ENE has tabled that the total hydroelectric potential of Angola exploitable using existing technologies is approximately $8200 \mathrm{MW}$. This comprises $6700 \mathrm{MW}$ from the middle Kwanza River in northern Angola (440MW developed to date), 968.4 MW from the Catumbela River in central Angola (79.4MW developed to date), and 311 MW from the Kunene River in southern Angola (40 MWdeveloped to date).

ENE expressed interest in developing this resource and exporting the energy to WESTCOR and other customers in SAPP. On the lower Kunene end and towards North- 
ern Namibia, Nampower will also participate and contribute supplies especially during peak periods.

Background material for developing energy in the African continent and SAPP is given in References [2-5].

\section{Inga SITE: Energy Development and Power Gen-Eration}

Given Data: The Congo River Hydrology at the Inga Site

Average River Flow: $42000 \mathrm{~m}^{3} / \mathrm{sec}$

Seasonal Constant Flow Range: $\sim 30000 \mathrm{~m}^{3} / \mathrm{sec}$ Inter Annual Module: $40000 \mathrm{~m}^{3} / \mathrm{sec}$

Noted Minimum Low Water Flow: 1905

Noted Maximum Flood:

$83400 \mathrm{~m}^{3} / \mathrm{sec}$ in 1961

Noted Exceptional Flood: $92000 \mathrm{~m}^{3} / \mathrm{sec}$

The data is presented graphically in Figure 1.

The given capacity data for the existing power stations are provided in Table $\mathbf{1}$.

There are two approaches for the harvesting of electrical energy from the potential energy of the river. The first approach can be described as medium head potential energy harvesting driven by water continuity from the run of the river and the second approach can be described as high head potential energy harvesting driven by water continuity from a large capacity storage dam.

The first approach is in general much simpler and less costly as compared to the second approach. The first approach should be fully exploited before commencement of the second approach. The revenues earned from the first approach will be a valuable source of finance to support the development of the second approach.

\subsection{Recommendation 1}

WESTCOR recommends that we fully exploit and develop the medium head potential energy harvesting as driven by water continuity from the run of the river.

The hydraulic power that is naturally available at the Inga site is defined by (1):

$P=g \rho Q H$

where $P$ : hydraulic power in watts

$g:$ acceleration due to gravity $=9.81 \mathrm{~m}^{2} / \mathrm{sec}$

$\rho:$ liquid density in $\mathrm{kg} / \mathrm{m}^{3}$

$Q:$ flow in $\mathrm{m}^{3} / \mathrm{sec}$

$H$ : potential head in $\mathrm{m}$

For the case of water, $\rho=1000 \mathrm{~kg} / \mathrm{m}^{3}$; then the equation becomes:

$$
P=9.81 Q H \quad \text { kilowatts }
$$

and the electrical energy produced is given by:

$$
W=P \operatorname{t} \eta f \quad \text { kilowatt-hours }
$$

where $t$ : operating time in hours

$\eta$ : efficiency of the turbine-generator assembly,

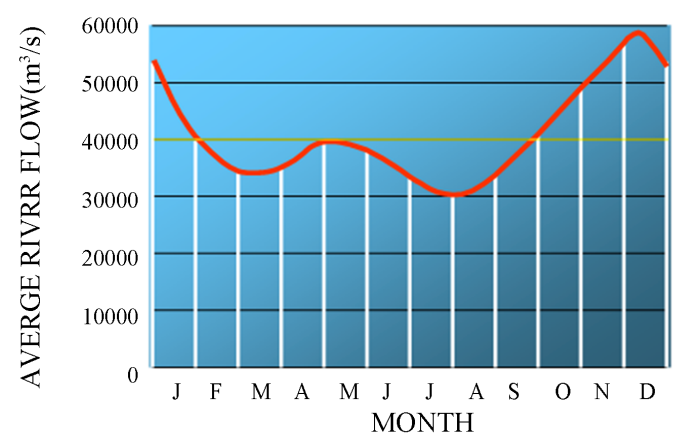

Historical Min(1905): Inter-annual Module Historical Max(1961):

$21.400 \mathrm{~m}^{3} / \mathrm{s} \quad 40.000 \mathrm{~m}^{3} / \mathrm{s} \quad 83.400 \mathrm{~m}^{3} / \mathrm{s}$

Figure 1. Typical river flow for January to December.

Table 1. Existing Power Station Capacity Data.

\begin{tabular}{cccc}
\hline Station & Head & Flow Rate & Capacity \\
\hline Inga 1 & $50 \mathrm{~m}$ & $780 \mathrm{~m}^{3} / \mathrm{sec}$ & $351 \mathrm{MW}$ \\
Inga 2 & $58 \mathrm{~m}$ & $2800 \mathrm{~m}^{3} / \mathrm{sec}$ & $1424 \mathrm{MW}$ \\
Total & & $3580 \mathrm{~m}^{3} / \mathrm{sec}$ & $1775 \mathrm{MW}$ \\
\hline
\end{tabular}

usually between 0.5 to 0.9

$f$ : coefficient to allow for seasonal variations to run of river flows

Applying the above equations to the standard data from the river hydrology records, we have the following scenarios [6,7]:

\subsubsection{Scenario 1: Power Potential at Average River \\ Flow Rate}

At the average river flow rate of $42000 \mathrm{~m}^{3} / \mathrm{sec}$ and using the same head as Inga 1 and 2 of $50 \mathrm{~m}$; we have:

Power Potential of the River in Run of River Mode $=$ $9.81 \times 42000 \times 50$ kilowatts

$$
P=20601 \mathrm{MW}
$$

\subsubsection{Scenario 2: Power Potential at Average River Flow Rate but Allowing for Continuous Gen- eration at Inga 1 and Inga 2}

Power Potential of the River in Run of River Mode $=$ $9.81 \times[42000-3580] \times 50$

$P=18845 \mathrm{MW}$ is available in addition to the full production at Inga 1 and 2.

\subsubsection{Scenario 3: Power Potential at Constant River Flow Rate and Allowing for Continuous Gen- eration at Inga 1 and 2}

Power Potential of the River in Run of River Mode $=$ $9.81 \times[30000-3580] \times 50$

$P=12959 \mathrm{MW}$ is available in addition to the full production at Inga 1 and 2.

This lower figure of $30000 \mathrm{~m}^{3} / \mathrm{sec}$ at constant flow rate can be considered an upper bound of what is possible at 
run of river application; fully allowing for Inga 1 and 2 continuous operation.

Over the last few years, two separate designs have been proposed for the Inga 3 power station. The first was prepared on the basis of an evolutionary design approach to continue along the Inga 2 open channel design; here more water was brought into the holding pools and an Inga 3, a $3600 \mathrm{MW}$ station was proposed; 8 machines at $450 \mathrm{MW}$ to yield a total of $3600 \mathrm{MW}$, using $6117 \mathrm{~m}^{3 /}$ $\mathrm{sec}$ and with a natural head of $60 \mathrm{~m}$. This was the Inga 3 allocated to WESTCOR for development.

A separate study by SNC Lavalin of Montreal prepared another sitting of Inga 3 with a collection of underground tunnels feeding the machines. Water is extracted at a point above the holding pools and is fed directly into the machines; with a natural head of $100 \mathrm{~m}$. Here the planned output was 4320 MW.

Both the $3600 \mathrm{MW}$ and the $4320 \mathrm{MW}$ design options are available for development as the river has the capacity to support both. The total is $7920 \mathrm{MW}$ and is well within the constant flow of the river. For both options, the designers should be challenged to increase both capacities to $5000 \mathrm{MW}$ such that even at $10000 \mathrm{MW}$, we still have a gap to the 12959 MW first boundary limit. Any drop in water flow will be reflected in an associated drop in energy sent out and this will vary with time and is manageable with system reserves.

\subsection{Recommendation 2}

The open channel design based on the Inga 2 concept is named the Inga 3 Power Station.

Planned Capacity: $3600 \mathrm{MW} ; 8$ machines each of 450 MW rating; $60 \mathrm{~m}$ natural head

Design Challenge: $5000 \mathrm{MW}$

\subsection{Recommendation 3}

The SNC Lavalin Study providing for a power station of capacity of 4320 MW and based on a collection of underground tunnels at a natural head of $100 \mathrm{~m}$ be named Inga 4. This would be similar to Eskom Drakensberg Power Station located in Bergville, South Africa [8].

Planned Capacity: 4320 MW; 100 m natural head.

Design Challenge: $5000 \mathrm{MW}$.

The sitting of both Inga 3 and Inga 4 is at different points on the banks of the Congo River and work can commence on sites simultaneously. There is a large physical separation between both power stations.

\subsubsection{Scenario 4: The Conventional Dam}

Preliminary analysis shows that the installation of a conventional dam in the path of the river flow would have the following potential impact on the natural environment:

1) The river flow is arrested and no water flows into the ocean. At present, the river flows for many kilometers into the ocean and thus fresh water is displaced gradually with the salt water of the ocean. Halting fresh water flow would have the reverse effect; the salt water would intrude into the gap left by the fresh water stoppage and the salt water would destroy all life dependent on fresh water. The intrusion of the salt water would be some $50 \mathrm{~km}$ inland and this would cause irreversible environmental harm to all living matter and organisms at the river mouth.

2) Arresting the Congo River with its high and regular flows would have the effect of pushing back the water levels on the river itself. Much of Kinshasa and neighborring Congo Brazzaville through which the river passes would be submerged by the rising water levels. Preliminary analysis of the land contours show a flat profile in the immediate vicinity of the river and this would create a massive lake that could stretch across Central Africa.

It is thus preferred that much of the river must continue to flow as naturally as possible; keeping the impact on the environment to an absolute minimum. Once we have exploited the full potential of the run of river capability, one could consider storage for those times when the river flow is much higher than the normal constant flow. This would afford a further development based more on water retention only when such time permits and then a further development of power generation capability as in stored water when available. More work is necessary to develop the concept of Grand Inga Cascades rather than Grand Inga Dam. In the case of water cascades, the same water could be employed several times for power generation before being released back into the river. With sound engineering, much more output can be extracted with no impact on the environment.

\section{Conclusions}

The shareholder benefits from Inga 3 development sustains and in summary, we have:

1) An annual income to the DRC Government of USD $500 \mathrm{~m}$ for the use of the water as primary energy.

2) Given natural, renewable energy employment, this annual revenue flow to the DRC Government will occur every year, indefinitely. In two years, this equates to USD 1 billion; a substantial contribution that can go towards developing the schools, hospitals, communities... towards a better quality of life for all the people of the DRC.

3) The delivery of the world's lowest cost wholesale tariff to all the five customers as in SNEL, ENE, Nampower, BPC and Eskom.

4) Payback of interest on capital and capital debt; within 10 years WESTCOR will enjoy debt free assets worth USD 5 billion. 
5) Shareholder dividends are declared once all assets are free; WESTCOR will continue to operate as a company for neither profit nor loss.

6) Payments for servitude concessions and real estate rates and taxes.

7) Payments for contracting services for operating and maintenance.

8) The WESTCOR annual revenues of USD 2.12 billion is effectively employed to pay for the assets, to pay for the primary energy, to pay for the operating expenses and in summary, is given back to all the shareholders.

This project of collective development represents the best investment for each shareholder and will go a long way to making a contribution to the economic renaissance of SADC and Continental Africa.

\section{REFERENCES}

[1] Monition, le Nir and Roux. "Micro Hydroelectric Power Stations," John Wiley and Sons, Paris, 1984.

[2] T. J. Hammons and P. Naidoo, "Africa: Integrated Gas and Electricity Transmission Planning in Power Generation and HVDC Engineering in Harnessing Large-Scale
Hydroelectric Sites for Interconnected Regional Power Systems," Journal Energy Systems, Springer, Berlin \& Heidelberg, ISSN 1868-3967, Vol. 1, No. 1, February 2010, pp. 79-112.

[3] T. J. Hammons, "Status of African and Middle-East Renewable Energy Projects: Infrastructure, Developments and Cross Border," International Journal of Power and Energy Systems, Vol. 30, No. 2, 2010, pp. 203-4320. doi:10.2316/Journal.203.2010.2.203-4320

[4] T. J. Hammons, "The Global Financial Crisis and its Impact on the Southern Africa Power Pool (Part 1)," Energize, South Africa, July 2009, pp. 43-48.

[5] T. J. Hammons, "The Global Financial Crisis and its Impact on the Southern Africa Power Pool (Part 2)," Energize, South Africa, August 2009, pp. 30- 35.

[6] "Small Scale Hydroelectric Schemes," Electricite de France International, EDF Paris, 1990.

[7] "Hydro Power in Sweden," The Swedish Power Association, Svenska Kraftverksforeningen, Stockholm, 1981.

[8] "Drakensberg Pumped Storage Scheme," The Transactions SAIEE, Johannesburg, 1982. 